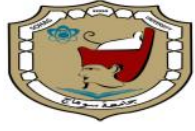

Sohag University

\title{
Cardiovascular System involvement in systemic lupus erythematosus (SLE)
}

\section{Mohammed Ezzat Amin', Mohamed Ibrahim Elsayed', Hany Ahmed Mohammed ${ }^{1}$, Asmaa Ahmed Abdel baset ${ }^{1}$, Sara Elsayed Kasem².}

1- Internal Medicine Department, Faculty of Medicine, Sohag University, Sohag, Egypt.

2- Forensic Medicine\& Clinical Toxicology Department, Faculty of Medicine, Sohag University, Sohag, Egypt.

\begin{abstract}
:
The systemic lupus erythematosus (SLE) is considered the most important autoimmune disease which affects most body organs and systems. SLE is mostly diagnosed in middle-aged females. However, it can affect any age and both genders. Lupus patients may present with minor skin and joint symptoms up to critical internal organ damage. Both clinical and laboratory findings are needed for sure diagnosis.

Cardiac disease is frequent in about $50 \%$ of lupus patients, but usually asymptomatic. However, they are critical and life-threatening, mostly due to premature and accelerated atherosclerosis. Therefore, the American Heart Association considers female patients with SLE as a high-risk group for the development of cardiovascular (CV) disease.

Lately, the rate of survival of lupus patients has improved, but the patient is still at high risk of CV morbidity and mortality.

Cardiovascular System involvement in systemic lupus erythematosus includes pericardial involvement, myocardial involvement, valvular disease, and coronary artery disease.

Cardiac diseases are common in lupus patients ${ }^{(1)}$. Although most of them are clinically silent, cardiac diseases in lupus can cause significant morbidity and mortality (2). Nowadays, the survival rate of lupus patients has increased, however, the cardiovascular (CV) mortality and morbidity are high ${ }^{(3)}$. Lupus patients have about 7 times higher CV risk and death rates when compared with the overall population ${ }^{(4)}$. So, the American Heart Association includes Lupus patients, especially women, as a highrisk group for $\mathrm{CV}$ disease ${ }^{(5)}$.
\end{abstract}

Keywords: SLE; cardiovascular; Heart disease

\section{Pericardial involvement}

Pericarditis occurs in 11- 54\% of Lupus patients. Infrequently, pericarditis may occur due to other causes as viral, uremia, tuberculosis ${ }^{(6)}$.

\section{Clinical picture}

Retrosternal or precordial chest discomfort (aggravated by lying down), dyspnea, and palpitations. Tamponade and constrictive pericarditis are rare $^{(7)}$.

\section{Investigation:}

ECG may exhibit sinus tachycardia, PR depression, and widespread ST elevation.

Transthoracic echocardiogram (TTE) is important for diagnosis ${ }^{(7)}$. Cardiac computed tomography (CT) and/or MRI are helpful in case of constrictive pericarditis ${ }^{(8)}$. 


\section{Myocardial involvement}

Myocarditis

Myocardial involvement can occur in 3$9 \%$ of SLE patients ${ }^{(1)}$. Recently, its prevalence is $0-8 \%$ due to the widespread usage of corticosteroids in lupus patients ${ }^{(9)}$.

\section{Clinical picture}

Fever, dyspnea, chest pain, palpitation resting tachycardia, gallop rhythms, jugular venous distention, and new cardiac murmurs ${ }^{(10)}$.

\section{Investigation}

ECG exhibit sinus tachycardia, widespread ST and T wave changes, arrhythmias, and conduction defects.

TTE measures the degree of ventricular dysfunction and low ejection fraction has been observed in most patients ${ }^{(11)}$. Cardiac MRI is the best choice in the diagnosis of non-ischemic inflammation of the myocardium and so lupus myocarditis ${ }^{(12)}$.

\section{Cardiomyopathy}

Lupus can cause cardiomyopathy directly due to disease activity or secondary due to CAD and/or hypertension. Also, cardiomyopathy secondary to hydroxychloroquine has been rarely reported ${ }^{(13)}$. Sure diagnosis requires an endomyocardial biopsy to exclude Fabry's disease ${ }^{(14)}$.

\section{Valvular Disease}

In lupus, it is believed that valvular affection is the most common CV disease. It comprises valvular masses (LibmanSacks vegetations), valvular thickening, valve regurge, and stenosis ${ }^{(15)}$.

It was reported that valvular disease cannot be prevented or cured by using steroids and/or immunosuppressives in the treatment of lupus patients ${ }^{(7)}$.

\section{Clinical picture}

Verrucous endocarditis is usually asymptomatic or may lead to cardiac murmur ${ }^{(16)}$. Mild regurge of the aortic and mitral valves are frequently noticed, but valvular stenosis is uncommon ${ }^{(1)}$.

\section{Investigation}

Echocardiography is a valuable noninvasive technique to distinguish the valvular structure, vegetations, and degree of valvular dysfunction ${ }^{(17)}$. A transesophageal echocardiogram is the modality of choice for detecting valvular lesions in lupus patients ${ }^{(18)}$.

\section{Coronary artery disease (CAD)}

It is believed that $30 \%$ of the total SLE patients 'deaths are due to CAD ${ }^{(19)}$. Traditional CV risk factors do not clarify the advanced rates of CVEs reported in lupus patients, ${ }^{(20)}$.SLE - associated factors comprise global disease activity, disease duration, cumulative damage, aPL, and renal disease ${ }^{(21)}$. These factors lead to accelerated atherosclerosis and myocardial inflammation ${ }^{(22)}$.

\section{SLE-specific risk factors of Atheros- clerosis:}

\section{1-Disease activity \& duration:}

It was reported that an extended disease period is associated with carotid plaque (23) and coronary calcium scores. ${ }^{(24)}$.

\section{2-Renal disease:}

Chronic kidney disease (CKD) and ESRD are factors that increase CV morbidity and mortality. Also, hypertension and dyslipidemia may add to this high risk. ${ }^{(25)}$

\section{3-The role of SLE medications in} relation to cardiovascular risk: A-Glucocorticoid therapy

It is believed that a longer duration of steroid therapy and high steroid dosage is associated with a higher risk of atherosclerosis in lupus patients. ${ }^{(26)}$

However, Roman et al. reported that previous or recent use of prednisone may be athero-protective due to its anti-inflammatory effects (27).

\section{B-Antimalarial}

It is believed that antimalarials are protective against CVEs and linked with a better metabolic profile regarding lipid and glucose ${ }^{(28)}$. 


\section{The clinical picture of CAD}

Clinical manifestations are angina pectoris and myocardial infarction. The danger of $\mathrm{MI}$ is augmented 50-fold in young females with SLE ${ }^{(29)}$. Even after the correction of the traditional CV risk factors, the threat of MI is still higher 8fold ${ }^{(30)}$.

\section{Diagnostic approach}

Resting and exercise ECG are the standard techniques to detect CAD in lupus (31). Also, it is believed that the imaging of atherosclerotic plaques is helpful in diagnosis $^{(32)}$. There are invasive and non-invasive methods of imaging. Angiography is the best invasive imaging technique ${ }^{(33)}$. While, B-mode ultrasound $^{(34)}, \mathrm{CT}^{(35)}$, and MRI ${ }^{(36)}$ comprise the non-invasive procedures.

\section{References}

(1) Tincani A, Rebaioli CB, Taglietti M, et al: Heart involvement in systemic lupus erythematosus, antiphospholipid syndrom$\mathrm{e}$, and neonatal lupus. Rheumatology (Oxford) 2006; 45 Suppl 4:iv8-iv13.

(2) Prasad M, Hermann J, Gabriel S.E, et al: Cardiorheumatology: cardiac involvement in systemic rheumatic disease. Nat Rev Cardiol, 2015; 12(3):168-176.

(3) Gustafsson J.T, Simard J.F, Gunnarsson I, et al: Risk factors for cardiovascular mortality in patients with systemic lupus erythematosus, a prospective cohort study. Arthritis Res 2012; Ther 14(2): R46.

(4) Bertsias G, Cervera R, Boumpas T.D: Systemic lupus erythematosus: pathogenesis and clinical features. EULAR Textbook of Rheumatic Diseases. 1 ed. BMJ Group; 2012: 476-505.

(5) Mosca L, Benjamin E.J, Berra K, et al: Effectiveness-based guidelines for the prevention of cardiovascular disease in women--2011 update: a guideline from the American heart association. Circulation 2011; 123(11): 1243-1262.

(6) Buppajamrntham T, Palavutitoai N, Katchamart W: Clinical manifestation, diagnosis, management, and treatment out- come of pericarditis in patients with systemic lupus erythematosus. J Med Assoc Thai 2014; 97: 1234-1240.

(7) Miner J.J, Kim A.H: Cardiac manifestations of systemic lupus erythematosus. Rheum Dis Clin North Am 2014; 40(1):51-60.

(8) Oh J.Y, Chang S.A, Choe Y.H, et al: Transient constrictive pericarditis in systemic lupus erythematosus. Eur Heart J Cardiovasc Imaging 2012; 13(9): 793.

(9) Apte M, McGwin G, Vila' L.M, et al: LUMINA Study Group. Associated factors and impact of myocarditis in patients with SLE from LUMINA, a multiethnic US cohort. Rheumatology 2008; 47:362-367.

(10) Wijetunga $M$, Rockeson S: Myocarditis in systemic lupus erythemaatosus. Am J Med 2002; 113(5):419-423.

(11) Zhang L, Zhu Y.L, Li M.T, et al: Lupus myocarditis: a case-control study from China. Chin Med J (Engl) 2015; 128(19): 2588-2694.

(12) Seneviratne M.G, Grieve S.M, Figtree G.A, et al: Prevalence, distribution, and clinical correlates of myocardial fibrosis in systemic lupus erythematosus: a cardiac magnetic resonance study. Lupus. 2016; 25(6):573-581.

(13) Sumpter M.D, Tatro L.S, Stoecker W.V, et al: Evidence for risk of cardiomyopathy with hydroxychloroquine. Lupus 2012; 21(14):1594-1596.

(14) Tselios K, Gladman D.D, Harvey P, et al: Hydroxychloroquine-induced cardiomyopathy in systemic lupus erythematosus-a case report. J Clin Rheumatol 2016; 22: 287-295.

(15) Moyssakis I, Tektonidou M.G, Vasiliou V.A, et al: Libman-Sacks endocarditis in systemic lupus erythematosus: prevalence, associations, and evolution. Am J Med 2007; 120(7):636-642.

(16) Doria A, Petri M: Cardiac involvement in systemic lupus erythematosus. In: 
Doria A, Pauletto P, editors. The heart in systemic autoimmune disease. Amsterdam: Elsevier; 2004; p. 146-162.

(17) Plastiras S.C, Pamboucas C.A, Tektonidou M, et al: Realtime three-dimensional echocardiography in evaluating Libman- Sacks vegetations. Eur J Echocardiogr 2010; 11(2): 184-185.

(18) Roldan C.A, Qualls C.R, Sopko K.S, et al: Transthoracic versus transesophageal echocardiography for detection of LibmanSacks endocarditis: a randomized controlled study. J Rheumatol 2008; 35(2):224229.

(19) Schoenfeld S.R, Kasturi S, Costenbader K.H: The epidemiology of atherosclerotic cardiovascular disease among patients with SLE: a systematic review. Semin Arthritis Rheum. 2013; 43(1):77-95.

(20) Agarwal S, Elliott J.R, Manzi S: Atherosclerosis risk factors in systemic lupus erythematosus. Curr Rheumatol Rep. 2009; 11(4):241-247.

(21) Tselios K, Sheane B.J, Gladman D.D, et al: Optimal monitoring for coronary heart disease risk in patients with systemic lupus erythematosus: a systematic review. J Rheumatol. 2016; 43(1):54-65.

(22) Sherer Y, Zinger H, Shoenfeld Y: Atherosclerosis in systemic lupus erythematosus. Autoimmunity. 2010; 43(1):98102.

(23) Manzi S, Selzer F, Sutton-Tyrrell K, et al: Prevalence and risk factors of carotid plaque in women with systemic lupus erythematosus. Arthritis Rheum. 1999; 42(1):51-60.

(24) Von Feldt J.M, Scalzi L.V, Cucchiara A.J, et al: Homocysteine levels and disease duration independently correlate with coronary artery calcification in patients with systemic lupus erythemaatosus. Arthritis Rheum. 2006; 54(7):22202227.

(25) Drueke T.B, Massy Z.A: Atherosclerosis in CKD: differences from the general population. Nat Rev Nephrol. 2010; 6(12):723-735.

(26) Doria A, Shoenfeld Y, Wu R, et al: Risk Factors for subclinical atherosclerosis in a prospective cohort of patients with systemic lupus erythematosus. Ann. Rheum. Dis. 2003; 62, 1071-1077.

(27) Roman M.J, Shanker B.A, Davis A, et al: Prevalence and correlates of accelerated atherosclerosis in systemic lupus erythematosus. N Engl J Med 2003; 349(25): 2399-2406.

(28) Jung H, Bobba R, Su J, et al: The protective effect of antimalarial drugs on thrombovascular events in systemic lupus erythematosus. Arthritis Rheum 2010; 62: 863-868.

(29) Manzi S, Meilahn E.N, Prairie J.E, et al: Age-specific rates of myocardial infarction and angina in women with systemic lupus erythematosus: comparison with the Framingham study. Am J Epidemiol 1997; 145: 408-415.

(30) Esdaile J.M, Abrahamowicz M, Grodzicky T, et al: Traditional Framingham risk factors fail to fully account for accelerated atherosclerosis in systemic lupus erythematosus. Arthritis Rheum 2001; 44: 2331-2337.

(31) Mavrogeni S, Smerla R, Grigoriadou $\mathbf{G}$, et al: Cardiovascular magnetic resonance evaluation of paediatric patients with systemic lupus erythematosus and cardiac symptoms. Lupus. 2016; 25(3):289295.

(32) Tardif J.C, Lesage F, Harel F, et al: "Imaging biomarkers in atherosclerosis trials," Circulation: Cardiovascular Imaging, 2011; 4(3): 319-333.

(33) Liang H.D, Noble J.A, Wells P.N.T: "Recent advances in biomedical ultrasonic imaging techniques," Interface Focus, 2011; 1(4): 475-476.

34) Magnussen $C$, Thomson $R$, Juonala $\mathbf{M}$, et al:" Use of b-mode ultra-sound to examine preclinical markers of atheros- 
clerosis: image quality may bias associations between adiposity and measures of vascular structure and function," J. Ultrasound Med. 2011; 30(3): 363-369.

(35) Wintermark M., Jawadi S., Rapp J.H, et al:" High-resolution CT imaging of carotid artery atherosclerotic plaques," American Journal of Neuroradiology, 2008; 29(5): 875-882.

(36) Corti R, Fuster V:" Imaging of atherosclerosis: magnetic resonance imaging," European Heart journal. 2011; 32(14): 1709-1719. 